\title{
Cholesterol Side-Chain Cleavage Deficiency
}

National Cancer Institute

\section{Source}

National Cancer Institute. Cholesterol Side-Chain Cleavage Deficiency. NCI Thesaurus.

Code C131422.

CLAH due to loss-of-function mutations in the CYP11A1 gene, resulting in decreased or absent activity of the enzyme P450scc, which leads to reduced conversion of cholesterol to pregnenolone, the first step in steroidogenesis. 